\title{
Recreando agri-cultura: Conocimientos agroecológicos e identidades campesinas en un proceso de educación- investigación-acción en Chiapas, México
}

\footnotetext{
iD Katrin Aiterwegmair ${ }^{1}$, ID Mateo Mier y Terán Giménez Cacho ${ }^{2}$, iD Fernando Limón Aguirre ${ }^{3}$, iD Ulli Vilsmaier ${ }^{4}$, (iD) Juliana Merçon ${ }^{5}$, (iD) José Fernando López Hernández ${ }^{6}$, (iD Romina Martínez Velarde ${ }^{7}$

${ }^{1}$ El Colegio de la Frontera Sur. Departamento de Agricultura, Sociedad y Ambiente. Carretera Panamericana y Periférico Sur s./n., Barrio Ma. Auxiliadora. San Cristóbal de Las Casas, Chiapas, México. ${ }^{2}$ El Colegio de la Frontera Sur - Consejo Nacional de Ciencia y Tecnología. ${ }^{3}$ El Colegio de la Frontera Sur. ${ }^{4}$ Leuphana University Lüneburg, Alemania. ${ }^{5}$ Universidad Veracruzana. ${ }^{6}$ OCEZ-CNPA Chiapas. ${ }^{7}$ Instituto Mexicano para el Desarrollo Comunitario, A.C.
}

Autor para correspondência/Author for correspondence: katrin.kusy@estudianteposgrado.ecosur.mx

RESUMEN. El proceso transdisciplinario de educacióninvestigación-acción campesina, analizado en el presente artículo, ha tenido por objetivo la construcción de la agroecología en la teoría y la práctica por parte de la organización campesina OCEZ-CNPA en Chiapas, México. Aplicando una metodología basada en la Educación Popular y la Investigación-Acción Participativa, se han regenerado conocimientos agri-culturales, que poseen un potencial de transformación agroecológica. Estos conocimientos se sostienen en identidades y modos de vida campesinos que, a pesar de haber sido colonizados y fragmentados, siguen teniendo raíces profundas que resisten al paradigma de la modernidad. A partir del análisis colectivo de las vivencias y las memorias bioculturales campesinas se comprende el cambio agri-cultural, inducido por la 'revolución verde', como una ruptura ontológica y epistemológica. Con una praxis de investigación campesina decolonial se reivindicaron conocimientos, prácticas y valores, que han caracterizado la agricultura maya por milenios. Este análisis condujo a la concepción de una agroecología profunda que reconoce y rescata las ontologías y epistemologías campesinas, constitutivas de paradigmas otros, correspondientes a formas de pensar y habitar el mundo, que difieren del paradigma moderno.

Palabras clave: educación popular, investigación-acción participativa, epistemología campesina, investigación transdisciplinaria, agroecología profunda. 


\title{
Recreating agriculture-agroecological knowledge and peasant's identities in a process of education-research- action in Chiapas, Mexico
}

\begin{abstract}
The transdisciplinary and peasant-based process of education-research-action analysed in this article aims at the construction of agroecology in theory and practice by the peasants' organization OCEZ-CNPA in Chiapas, Mexico. Conducting a methodology based on Popular Education and Participatory Action Research, agri-cultural knowledge has been regenerated, constituting potential for profound agroecological transformation. This knowledge relies on identities and ways of life that, despite having been colonized, continue to have deep roots that resist the paradigm of modernity. The collective reflection of the peasants' experiences and biocultural memories have made the agri-cultural change induced by the 'green revolution' understood as an ontological and epistemological rupture. With this peasant-based and decolonial research, knowledge, values and practices, that have been characterizing the Mayan agriculture for thousands of years, have been reclaimed. This analysis has led to the conception of a deep agroecology that acknowledges and recovers the peasants' ontologies and epistemologies, constitutive of other paradigms, corresponding to forms of thinking of and living in the world that differs to those of the modern paradigm.
\end{abstract}

Keywords: popular education, participatory action research, peasants' epistemology, transdisciplinary research, deep agroecology. 


\section{Recriando agricultura: conhecimentos agroecológicos e identidades camponesas em um processo de educação- pesquisa-ação no Chiapas, México}

RESUMO. O processo transdisciplinar de educação-pesquisaação camponesa, analisado neste artigo, tem sido direcionado à construção da agroecologia em teoria e prática pela organização camponesa OCEZ-CNPA em Chiapas, México. Ao aplicar uma metodologia baseada na Educação Popular e na Pesquisa-Ação Participativa, o conhecimento agro-cultural foi regenerado, o que tem o potencial para a transformação agroecológica. Este conhecimento é baseado em identidades camponesas e modos de vida que, apesar de terem sido colonizados e fragmentados, continuam tendo raízes profundas que resistem ao paradigma da modernidade. A partir da análise coletiva das experiências e memórias bioculturais camponesas, a mudança agro-cultural induzida pela 'revolução verde' é entendida como uma ruptura ontológica e epistemológica. Com uma praxis de pesquisa camponesa descolonial, os conhecimentos, práticas e valores que caracterizaram a agricultura maia durante milênios foram recuperados. Esta análise levou à concepção de uma agroecologia profunda que reconhece e resgata ontologias e epistemologias camponesas, constitutivas de outros paradigmas, correspondentes a formas de pensar e habitar o mundo, que diferem do paradigma moderno.

Palavras-chave: educação popular, pesquisa-ação participativa, epistemologia camponesa, pesquisa transdisciplinar, agroecologia profunda. 


\section{Introducción}

En el presente artículo se comparten perspectivas ontológicas, epistemológicas y metodológicas manifestadas en un marco agroecológico, que han surgido en un proceso de investigación colaborativa en Chiapas, México. Se trata del Proceso de Educación-Investigación-Acción

Campesina, en lo adelante Proceso, que se viene realizando en Chiapas, en el sureste de México, desde el año 2016 por un equipo transdisciplinario. El mismo se conforma por campesinas y campesinos integrantes de la Organización Campesina Emiliano Zapata - Coordinadora Nacional Plan de Ayala (OCEZ-CNPA), educadoras populares del Instituto Mexicano para el Desarrollo Comunitario (IMDEC) e investigadoras/os sociales $\quad \mathrm{y}$ agroecológicos. El objetivo de este Proceso ha sido construir conocimiento, generar conciencia y promover acción colectiva para fortalecer la agroecología y la soberanía alimentaria entre las familias campesinas que integran la OCEZ-CNPA Chiapas. El artículo aborda los conocimientos campesinos surgidos en el Proceso, los cuáles muestran una potencia transformadora favorable a la agroecología.

La agroecología es considerada movimiento social, praxis y ciencia (Wezel et al., 2009), que se construye a través de un diálogo de saberes (Rosset \& Martínez, 2014), con el propósito de entender y a la vez transformar la realidad (Ruiz, 2006; Méndez et al., 2013). A este mismo objetivo aportan metodologías de investigación y educación críticas, transdisciplinarias y participativas, como la Educación Popular (EP) propuesta por Freire (1972; 2002) y la InvestigaciónAcción Participativa desarrollada por Fals Borda (1979). La presente investigación se estructura sobre la base de estas metodologías relacionadas con la intención de analizar un proceso educativo que busca ser emancipador al remitir la agroecología a una praxis campesina de pedagogía crítica y decolonial (Walsh, 2014). Consecuentemente, la perspectiva pedagógica y epistemológica se ubica dentro del enfoque de aprendizaje e investigación de Paulo Freire según el cual el "[s]aber sólo existe en la invención, en la reinvención, en la búsqueda inquieta, impaciente [... que las personas] realizan en el mundo, con el mundo y con los otros" (Freire, 2002, p. 52). En esta concepción, el conocimiento no es universal sino situado en un contexto cultural e histórico de un sujeto político y epistémico concreto (Freire, 1972).

A pesar de que la agroecología es una transdisciplina, que se construye en un 
diálogo entre conocimiento científico y conocimiento campesino, en la presente investigación se hace énfasis en el sujeto campesino y sus conocimientos agriculturales. $\mathrm{Su}$ "saber vivir aquí", como Limón (2010; 2019) describe a este tipo de conocimiento situado en un territorio con una historia particular, sostiene la agricultura campesina. La expresión de agricultura con guion tiene la intención de subrayar la esencia cultural de la agricultura. Acorde con Giraldo (2018), la agricultura constituye el "origen de las representaciones culturales, las aprehensiones cognitivas, las identidades y los significados colectivos", por lo que "la agricultura es profundamente ontológica" (p. 80). La presente búsqueda de conocimiento campesino con potencia emancipadora y transformadora remite a esta comprensión de la agroecología como un modo de vida campesino.

El artículo está estructurado de la siguiente manera: introducimos con una perspectiva epistemológica de la agroecología a la temática, que conduce a la concepción metodológica, abordada en la sección subsiguiente. A posteriori, se presenta al sujeto epistémico y político de la investigación: la organización campesina OCEZ-CNPA. El apartado de resultados se compone de cuatro subsecciones que entretejen los conocimientos agri-culturales de las y los campesinos (sus epistemes), sus fundamentos en modos de ser, de vivir y de ver la vida (su sustento ontológico) y sus maneras de regenerarse (dinámicas metodológicas y gnoseológicas en el Proceso). La comprensión campesina de la agroecología como su agri-cultura campesina ancestral inspira a la concepción de una agroecología profunda (Botelho et al., 2016; García et al., 2019; McFadden, 2019), que se encuentra arraigada en ontologías campesinas y que se manifiesta en la memoria, los valores y las prácticas de relacionarse con la tierra, el territorio y con la comunidad.

\section{Una perspectiva epistemológica de la agroecología}

Un motivo del presente estudio es reconocer y contrarrestar al epistemicidio, como Santos (2010) y otros/as autores denominan la opresión, asimilación, marginación, sustitución y destrucción de conocimientos indígenas y campesinos por el sistema hegemónico de producción y valoración de conocimientos. Acorde con esta crítica, Leff (2006) constata que la crisis ambiental y civilizatoria actual es "generada por el desconocimiento del conocimiento", por lo que demanda “cuestionar el pensamiento y el entendimiento del mundo, la ontología, la 
epistemología y la ética con las que la civilización occidental ha comprendido el ser, los entes y las cosas" (pp. 24-25).

La agroecología, en su comprensión transdisciplinaria, implica "reflexionar sobre la práctica científica misma" (F. Gómez et al., 2015, p. 685) y crear metodologías que faciliten "un pluralismo epistemológico para la producción de conocimiento agrario" (Floriani y Floriani, 2010, citado por F. Gómez et al., 2015, p. 682). Dado que la agroecología origina en la agricultura tradicional campesina e indígena (Gliessman, 1981; Xolocotzi \& Zárate, 1991), busca rescatar "saberes y sentires que han guiado a los diversos pueblos en su construcción de cultura y reproducción social a través de la historia humana" (Altieri \& Toledo, 2010, p. 170). Sevilla (2006) subraya que la agroecología

se basa en el descubrimiento, en la sistematización, análisis y potenciación de los elementos de resistencia local frente al proceso de modernización para diseñar, de forma participativa, estrategias de desarrollo definidas a partir de la propia identidad local del etnoagroecosistema concreto en que se insertan" (p. 211).

El conocimiento agroecológico es situado y comparte el criterio de la Investigación-Acción Participativa de aportar "tanto el nivel de eficacia de la acción como el entendimiento de la realidad" (Fals Borda, 1979, p. 12), para construir "una nueva relación de la sociedad con la naturaleza" (Altieri \& Toledo, 2010, p. 180). Diversos autores y organizaciones se empeñan a favor de la agroecología como un verdadero cambio de paradigma (IPES-Food, 2016; IAASTD, 2009; UNCTAD, 2013; Pimbert, 2006). Ante este reto proponen emprender una democratización y descentralización del conocimiento para refundar epistemologías agroecológicas acordes con las vivencias y memorias de los pueblos originarios y de los movimientos sociales y campesinos (Altieri \& Toledo, 2010, p. 180).

El presente estudio se suma al compromiso científico de crear espacios sociales que faciliten el diálogo de saberes (Rosset \& Martínez, 2014) y de “investigar las condiciones de un diálogo horizontal entre conocimientos" (Santos, 2010, p. 57), coincidiendo con Santos (2010) que "todo el conocimiento es interconocimiento" ( $p$. 49). En lo siguiente, se resume el diseño metodológico, con el cual se aspiró llevar estas concepciones epistemológicas a la práctica.

\section{La metodología transdisciplinaria del Proceso de Educación-Investigación- Acción Campesina}

El estudio realizado se sustenta en las metodologías relacionadas a la Investigación-Acción Participativa (Fals Borda, 1979) y a la Educación Popular 
(Freire, 1972; 2002). Estas combinan igual que la agroecología - la intencionalidad epistemológica y política al buscar tanto la comprensión de la realidad como su transformación. Con estas concepciones metodológicas de carácter transdisciplinario en su sentido "transgresivo o transformador del status quo" (Merçon et al., 2018, p. 20) y transversal, se busca afianzar el análisis en una unidad de conocimiento entre ciencia, espiritualidad, cultura y socio-política (Guattari, 2015; Nicolescu, 2008; Vilsmaier et al., 2017). Aplicamos la transdisciplina en nuestro estudio como "un marco integrador de diferentes tipos de conocimiento", que involucra también "prácticas, valores e intereses" (Merçon et al., 2018, p. 20).

La investigación toma como punto de partida el 'aquí y ahora' del sujeto campesino de investigación-acción (Freire, 2002), insertándose en su proceso pedagógico y socio-político, realizado desde el 2016 en dos etapas: 1. La Sistematización de Experiencias en Aprendizajes-Enseñanzas Agroecológicas (SALE; realizado de 2016 a 2018 y coordinado por el Instituto Paulo Freire Austria) y 2. la Acción Sociopolítica para la Defensa de la Tierra y del Territorio (ASODETTE; vigente desde 2018 hasta la actualidad, coordinado por el Instituto
Mexicano para el Desarrollo Comunitario IMDEC).

En el esfuerzo de crear una colaboración transdisciplinaria (Merçon et al., 2018), hemos dado énfasis en construir relaciones horizontales entre investigadores académicos e investigadores de la praxis. Los últimos, campesinos y campesinas de la OCEZ-CNPA, son los conocedores de su realidad y agentes de su transformación (“driver of change" según Van der Ploeg, 2011), por lo que tienen un papel protagónico en la construcción de conocimiento. Mientras que las y los académicos han acompañado, facilitado, observado, sistematizado y analizado el Proceso. Esta $\quad$ constelación transdisciplinaria del equipo investigador rompe con fronteras epistemológicas y ontológicas (Mignolo, 2003; Vilsmaier et al., 2015), dado que investigadores de la praxis están involucrados en la producción de teoría e investigadores académicos participan en la praxis campesina.

La investigación está compuesta por tres dimensiones con diferentes enfoques en actores, métodos y actividades, que a la vez están estrechamente vinculadas a través de su comunicación sistemática, y unidas en su objetivo común de construir (conocimiento sobre) una educacióninvestigación-acción campesina de la 
agroecología. La tabla siguiente resume

sus características principales.

Tabla 1 - Las dimensiones de la investigación transdisciplinaria.

\begin{tabular}{|c|c|c|c|}
\hline $\begin{array}{l}\text { Dimensión de } \\
\text { investigación }\end{array}$ & Participantes & $\begin{array}{c}\text { Metodologías y } \\
\text { métodos }\end{array}$ & Objeto de análisis \\
\hline $\begin{array}{l}\text { 1. Investigación } \\
\text { campesina } \\
\text { colaborativa } \\
\text { ("el Proceso") }\end{array}$ & $\begin{array}{l}\text { Campesinos/as, } \\
\text { coordinadores, } \\
\text { facilitadores e } \\
\text { investigadores académicos } \\
\text { (grupo completo) }\end{array}$ & $\begin{array}{l}\text { Educación Popular, } \\
\text { Sistematización de } \\
\text { Experiencias, } \\
\text { Investigación-Acción } \\
\text { Participativa }\end{array}$ & $\begin{array}{l}\text { La situación de las/los campesinos } \\
\text { y de sus tierras y territorios en el } \\
\text { contexto colonial-capitalista- } \\
\text { patriarcal, igual que su propia } \\
\text { praxis en relación a esta situación }\end{array}$ \\
\hline $\begin{array}{l}\text { 2. Reflexión, } \\
\text { evaluación y } \\
\text { planeación del } \\
\text { Proceso (1.) }\end{array}$ & $\begin{array}{l}\text { equipo transdisciplinario } \\
\text { de coordinación, } \\
\text { facilitación e investigación }\end{array}$ & $\begin{array}{l}\text { Diálogo auto-crítico } \\
\text { estructurado }\end{array}$ & $\begin{array}{l}\text { Reflexión del Proceso en relación } \\
\text { con el contexto y la situación de la } \\
\text { organización } \rightarrow \quad \text { planeación } \\
\text { estratégica (mirada retrospectiva y } \\
\text { prospectiva) }\end{array}$ \\
\hline $\begin{array}{l}3 . \quad \text { Análisis } \\
\text { profundo del } \\
\text { Proceso (1.) y } \\
\text { su reflexión (2.) }\end{array}$ & $\begin{array}{l}\text { Investigadores } \\
\text { (doctoranda y consejo } \\
\text { tutorial integral, } \\
\text { compuesto de } \\
\text { investigadores académicos } \\
\text { e investigadores de praxis) }\end{array}$ & $\begin{array}{l}\text { Observación } \\
\text { participante, } \\
\text { documentación, } \\
\text { sistematización y } \\
\text { análisis del Proceso } \\
\text { (apoyado en la } \\
\text { Grounded Theory) }\end{array}$ & $\begin{array}{l}\text { El (proceso de construcción de) } \\
\text { conocimiento que aporte a la } \\
\text { concepción y praxis de una } \\
\text { agricultura } \\
\text { agroecológica }\end{array}$ \\
\hline
\end{tabular}

Fuente: Elaboración propia.

Las tres dimensiones son elementos constitutivos del proceso de investigación, diferenciándose por el nivel de abstracción del conocimiento generado, que gana en desarrollo en su transcurso de la primera hacia la tercera dimensión. Su núcleo es el Proceso ubicado en la primera dimensión, que está en diálogo con la segunda dimensión, siguiendo la dinámica dialéctica de acción y reflexión, que según Freire (2002) constituye la praxis emancipadora. La investigación académica participa en las otras dimensiones y se orienta a ellas. A continuación, se resumen las características y procedimientos metodológicos principales de cada una de las dimensiones, con un enfoque en sus metodologías de análisis.
[1] El Proceso de investigación campesina colaborativa se ha realizado a través de actividades grupales, como talleres $\mathrm{y}$ visitas a las comunidades campesinas, aplicando métodos y técnicas participativas, creativas, prácticas, reflexivas y lúdicas. Se destacan aquellos provenientes de la Investigación-Acción Participativa, que fueron dirigidas al reconocimiento de la situación de la tierra y el territorio, igual que al análisis de la propia praxis y las experiencias en temas de agricultura, organización y educación. Con formas de comunicación creativa (como artes plásticas, sociodramas, canciones, poesía y dibujos, ejemplificadas en las ilustraciones 1-3), los sub-grupos de investigación devolvieron sus resultados al 
resto del grupo. Las expresiones estéticas y sus reflexiones colectivas se realizan en una iteración entre codificación y descodificación de la realidad para analizar la misma de manera (auto)crítica (Freire, 2002). Esta metodología dialéctica, propuesta por Freire (2002) como camino de concientización y humanización, ha revelado los "temas generadores" (p. 90), siendo los temas significativos para crecer enfrentando la realidad. Las siguientes dimensiones reflexivas se dedicaron a su profundización.

[2] El Proceso se acompaña de la evaluación y planeación continua y sistemática. La reflexión colectiva y crítica de la praxis y sus resultados, en articulación con la situación general de la organización en el contexto actual, ha aportado tanto a la planeación iterativa del Proceso como a la profundización del análisis. Esta dimensión además forma el puente entre las otras dimensiones, disponiendo de un espacio de diálogo para devolver los resultados preliminares de la investigación académica y contrastarlos con las perspectivas de la praxis.

[3] La tercera dimensión se refiere a la investigación académica en su sentido estricto. Se dedicó principalmente a la documentación y sistematización del Proceso y a la profundización de los temas generadores destacados en él. Estos temas se contrastaron en una triangulación de fuentes (personas), momentos $\mathrm{y}$ dimensiones del Proceso, en articulación con teoría que aporta a la comprensión y complejización de los temas generadores. La metodología de análisis de la Grounded Theory (Glaser \& Strauss, 1990), basada en la lógica de abducción (Reichertz, 2010), aportó a la construcción de teoría desde la praxis. Los resultados de esta otra etapa de codificación, han sido socializados con el equipo investigador de praxis, en aspiración que "los propios resultados de la investigación se reintroduzcan en el mismo proceso para profundizar en la misma" (Villasante, 1994, p. 9, citado por Jara, 2012, p. 63).

El contenido del artículo se creó en esta última dimensión, basándose en el análisis de los temas generadores del Proceso. En la sección subsiguiente se comparten algunos de los resultados respectivos, exponiendo ejemplos de codificación en forma de dibujos, y su reflexión crítica, que descodifica la situación representada al aterrizarla a la praxis concreta. Un sistema de códigos hace referencia a las fuentes primarias, indicando la actividad, su lugar y fecha, que se encuentran al final del texto. Reconociendo que el conocimiento presentado surge principalmente de las $\mathrm{y}$ los investigadores de la praxis, se decidió 
en consentimiento colectivo visibilizar sus nombres en las citas, para no discriminarlos frente a autores de conocimiento escrito. A continuación, se presenta el sujeto investigador campesino desde su contexto histórico y sus retos presentes.

\section{La OCEZ-CNPA como sujeto político y epistémico desde una perspectiva histórica}

El sujeto político y epistémico de la investigación es la Organización Campesina Emiliano Zapata, formando parte de la Coordinadora Nacional Plan de Ayala. En el Proceso han participado alrededor de 60 hombres y mujeres campesinas, militantes y dirigentes de la OCEZ-CNPA Chiapas. La mayoría tiene entre cuarenta y sesenta años y habita comunidades en los municipios La Trinitaria, Frontera Comalapa, Amatenango de la Frontera, Comitán de Domínguez y Escuintla de la región Fronteriza del estado de Chiapas, México.

La OCEZ-CNPA es una organización de base, que lleva en su bandera la lucha de Emiliano Zapata "por la tierra, la justicia, la libertad y la democracia" (OCEZ-CNPA, 2015). Estas demandas de carácter histórico no han perdido validez durante sus más de cuarenta años de existencia, dado que se las ha ido actualizando. Hoy, se interpreta la lucha por la tierra también como la lucha por una tierra sana, fértil y comunitaria, en correspondencia con la agroecología y la soberanía alimentaria. La ideología de la OCEZ-CNPA se funda en el marxismoleninismo y la praxis cristiana de la teología de liberación. Esta praxis resultó clave en el proceso de concientización y organización de las comunidades campesinas en los años setentas y ochentas del siglo pasado y contribuyó decisivamente a la fundación de la organización en el año 1982. La iglesia católica de la opción preferencial por los pobres, promovió principios de trabajo de base, de educación popular y de organización colectiva (OCEZ-CNPA, 2019). Estos principios fundacionales de la expresa organización aspiran a aportar a su meta de transformación social que, para sus dirigentes significa "crear hombres y mujeres nuevas" (SALE, 2019), según la proclama de la teología de liberación, igual que la del Che Guevara (2003) y de Fanon (2001).

A partir de los primeros años de los noventa, habiendo sufrido fuertes represiones por parte del Estado, y padecido conflictos y divisiones en su interior en un contexto de consolidación del neoliberalismo, la OCEZ-CNPA se fue transformando, dejando al lado sus principios, lo que ha sido analizado 
reiteradamente en el transcurso del Proceso. Su amoldamiento y adaptación a las estrategias asistencialistas del gobierno mexicano afectó la praxis y subjetividad sociopolítica de la organización, como se colige de lo expresado por su dirección: "nos desorientó de nuestra razón de ser, como entes de transformación y cambio en los territorios; para convertirnos en gestores de apoyos económicos" (OCEZCNPA, 2019). De ahí, "romper con la dinámica clientelista" (SALE, 2019) ha sido identificado por la dirigencia de la OCEZ-CNPA como el principal reto para fortalecer la agroecología desde la autogestión comunitaria. Para ello plantea "sembrar conciencia", retomando la educación popular como prioridad del trabajo de la organización.

Estas reflexiones auto-críticas de la OCEZ-CNPA trascienden al Proceso, más bien, han sido su motivación principal para desempeñar el Proceso de (auto)investigación campesina, cuyos resultados se analizan a continuación.

\section{Discusión de resultados}

Las cuatro sub-secciones siguientes se dedican a la discusión de resultados significativos del Proceso en diálogo con aportes teóricos. Presentan la situación en que se encuentran los y las campesinos y sus tierras y territorios, enfocando el análisis en el cambio agri-cultural vivido. La praxis decolonial de reconstruir la agricultura campesina desde la memoria biocultural (Toledo \& Barrera-Bassols, 2008) abre la perspectiva a la existencia de conocimientos agri-culturales, que sostienen una agroecología profunda.

Los/as campesinos/as y sus tierras y territorios situados entre "proyecto de muerte y proyecto de vida"

En varias reflexiones a lo largo del Proceso, las y los campesinos han interpretado la situación, en que se encuentran ellos y sus tierras y territorios, "entre proyecto de muerte y proyecto de vida" (visualizada en la ilustración 1). Esta noción hace referencia a los dos modelos agroalimentarios, la agricultura empresarial y la agricultura campesina, que están en disputa por la tierra y el territorio (Van der Ploeg, 2010; Rosset \& Martínez, 2016). Este conflicto "no sólo es una batalla de tierras per se (territorio material), también es una batalla de ideas (territorio inmaterial)", destacan Rosset y Martínez (2016, p. 279).

Una dirigente de la OCEZ-CNPA expuso en una entrevista el escenario en el campo, realizada por la co-investigadora académica Erika Nájera (2018):

Por una parte se encuentra un modelo sobre la base del tratado de libre comercio, sobre la base del 
consumismo $\quad \ldots$ de políticas asistencialistas, que crean dependencia, un modelo que pretende vaciar al campo de los campesinos, un modelo que está provocando la pérdida y la erosión de los conocimientos y prácticas agroecológicas, de conocimientos en semillas ... de la economía local y de relación espiritual, de relación con la tierra y con los semejantes; y por otro lado, el modelo que nosotros estamos recuperando, que es un modelo que pretende darle su lugar a la agricultura campesina, agricultura familiar, fortalecer la economía local, fortalecer la producción de alimentos. (p. 48).

En un ejercicio colectivo de reconocimiento de la situación de la tierra y del territorio (en el Segundo Encuentro Transfronterizo de ASODETTE con aliados/as de Guatemala y de los Altos de Chiapas), todos los cinco grupos de reflexión plasmaron esta dialéctica entre despojo y resistencia, entre amenaza y esperanza, en sus dibujos. Analizando las coincidencias de manera colectiva, las y los campesinos destacaron que las ilustraciones reflejan dos mundos: "En uno, lo que se aspira es que haya diversidad, herencia, armonía y equilibrio, y en el otro, se describe como devastación y explotación ... despojo y acumulación" (AE2). Un ejemplo de las diferentes expresiones estéticas de la situación entre proyecto de vida y proyecto de muerte se presenta en la ilustración 1. Según la explicación de quienes realizaron la obra, el tronco del árbol divide estos dos mundos. La parte derecha del árbol es dominada por el poder hegemónico. Un participante del pueblo maya q'anjob'al comparte el análisis colectivo representado en el siguiente dibujo:

\section{Ilustración 1 - "Entre proyecto de muerte y proyecto de vida”, producto de una reflexión colectiva sobre la situación de la tierra y el territorio.}

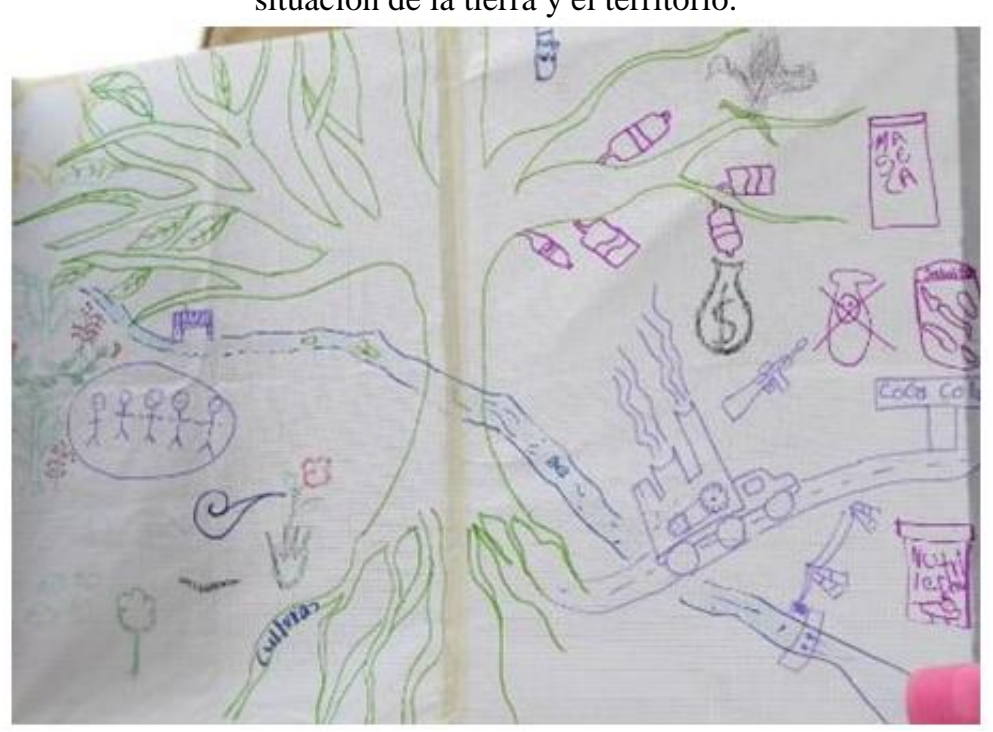

Fuente: Foto tomada por Katrin Aiterwegmair en el Segundo Encuentro Transfronterizo de ASODETTE (AE2).

\begin{tabular}{|l|l|l|l|l|l|l|} 
RBEC & Tocantinópolis/Brasil & v. 6 & e11925 & $10.20873 /$ uft.rbec.e11925 & 2021 & ISSN: 2525-4863 \\
\hline
\end{tabular}


Todo este tema del imperialismo nos va afectando en nuestras comunidades ... está enfermando a la Madre Tierra; pero no sólo a ella, sino también a nosotros ... Viendo en las comunidades se puede ver esa necesidad, todos los productos, que ha creado el mercado desde la CocaCola, la Maseca, las Sabritas y toda esta maquinaria, pues enferman cada vez más ... Las raíces allí son pocas, pues, es algo muy reciente y sus motivos son pocos ... Mientras en la otra parte hay una raíz milenaria. (AE2)

El lado izquierdo y esperanzador del árbol lo comenta una militante de la OCEZ-CNPA:

Está con sus hojas verdes; están los campesinos ... rescatando nuestra manera de trabajar; está la marimba; y algo simbólico de nuestras parcelas: hay diversidad, los árboles, el río y los abonos orgánicos. Aquí es el diálogo ... y esta parte de nuestras raíces, que es nuestra cultura. (AE2)

Este diagnóstico colectivo sobre la situación de las y los campesinos y sus tierras y territorios, haciendo énfasis en las raíces culturales como fuente de resistencia, introduce a la perspectiva analítica en la que se profundiza a continuación.

\section{La 'revolución verde' como ruptura epistemológica y ontológica}

Al inicio del Proceso buscamos entender cómo las y los campesinos han aprendido de la agroecología, cómo la comprenden y la practican. Un momento significativo en este contexto fue cuando una militante destacó que "lo llaman agroecología ahora, pero es lo que de por sí hacíamos antes" (SALE, 2019). Esta reapropiación campesina de la agroecología es fundamental, considerando su origen en el agroecosistema mesoamericano milenario basado en la milpa (Gliessman, 1981; Xolocotzi \& Zárate, 1991; Altieri \& Toledo, 2010). La milpa es un policultivo de variedades criollas de maíz en asociación con otros cultivos, principalmente frijol y cucurbitáceas (como calabazas), además de aceptar la presencia de una diversidad de arvenses comestibles, que se reproducen sin volver a sembrarlas cada año (siempre y cuando no se aplique herbicidas). Sin embargo, hoy también suele llamarse "milpa" al monocultivo de maíz.

Según la experiencia de los miembros de la OCEZ-CNPA, con la 'revolución verde', que llegó a la región Fronteriza de Chiapas en los años 1980s a inicios del período neoliberal (Harvey, 2007, p. 106), empezó a decaer este agroecosistema diverso, productivo $\mathrm{y}$ sustentable. En ejercicios sentí-pensativos que recuperan la memoria biocultural recordaron el cambio agri-cultural, que se dio en el transcurso de su vida.

[E]n los terrenos había de todo: chipilín, hierba mora, tepenchile, porque se cultivaba puro manual y 
sin medida de químico. Y el maíz para mí era puro, así natural, lo del criollo. Poco rendía, pero seguro ... Luego empezó con el fertilizante ... y con el tractor. Pero allí fue donde se fue empezando a perder, créenme. Cuando empezó el fertilizante, el líquido [químico], todo, ahora sí, acabó, la hierba mora, acabó el chipilín, por completo ... Y allí se fue dando cuenta de repente que el terreno va quedando pobre ... Y la milpa ya no, ya no producía. (Anselmo Vázquez, AT8)

En análisis colectivo, siguiendo el movimiento dialéctico entre las experiencias personales y el contexto económico, cultural y político desde una perspectiva histórica, las y los miembros de la organización llegaron a la conclusión que la modernización de la agricultura les ha empobrecido, a ellos igual que a sus tierras. Contrario al mito de que la modernización les sacaría de su "pobreza" y su "retraso" (ST2; AT8), ella ha provocado la pérdida de la diversidad y productividad de sus tierras y hasta de sus tierras. La "estrategia de endeudamiento" de otorgar créditos para comprar insumos agroquímicos, maquinaria y otras “necesidades creadas por la ideología del consumismo", les hizo "pagar doble el dinero" (AT8). Resaltaron que antes de la ‘revolución verde’ tenían más autonomía y soberanía alimentaria: "poca milpa se sembraba, pero daba mucho", "las mazorcas eran grandes" y siempre alcanzaba para el consumo familiar y para vender un excedente variable (ST2; AT8). Además, "era muy poco dinero que se invertía antes en comparación de hoy", simplemente, "no se trataba mucho de dinero" (AT8). Roberto Alvarado rememora los inicios de su labor agrícola en los años 1970s: "Para nosotros no había pobreza, porque teníamos que comer; y entre nosotros no había diferencias, nos veíamos parejos. Andábamos con ropa remendada y nadie hacía la diferencia. Además, había mucha salud" (AT2). "Después comenzó la pobreza, cuando vino la competencia" (ST2). El carácter relativo de pobreza resalta aún más en un comentario de Encarnación García sobre la impertinencia de hablar de "ganancia" en el modelo tipo 'revolución verde', porque

son las grandes empresas extranjeras que se llevan la ganancia $y$ peligrando la vida ... Y podemos decir, si te queda una ganancia para un año unos cinco mil o diez mil; ¿pero si te enfermas? ... ¿Si te mueres? ¿Cuánto vale una muerte ahora? Es algo que no podemos decir que hay ganancia; es pura inversión y mucho peligro. (AT8)

La salud es un tema prioritario para las y los campesinos. La mayoría de las y los participantes padece de enfermedades y el diagnóstico participativo indica en todas las comunidades visitadas un incremento de diabetes, obesidad y cáncer, que "antes no se conocían" (DPTA). Se las identificó como enfermedades civilizatorias 
relacionadas con la modernización de la agricultura y alimentación. Además, se han perdido los sistemas comunitarios de salud y conocimientos de la medicina tradicional holística, por dejar de creer en ella y optar por la "medicina de patente" (ST2; AT9), a la cual la mayoría no tiene acceso por sus altos costos.

El empobrecimiento se encuentra tanto en el nivel material como inmaterial, puesto que también se han ido perdiendo costumbres y valores comunitarios, tales como convivencia, solidaridad, reciprocidad, comunicación y respeto hacia las personas mayores (ST1; AT9). De ahí se resalta, retomando a Xolocotzi y Zárate (1991), que la agricultura moderna no sólo ha degradado "la diversidad biológica, de hábitats, de factores ambientales, de etnias y de poblaciones humanas", además ha creado "una cosmovisión materialista y egocéntrica" (p. 12). El vínculo entre las dimensiones materiales e inmateriales lo ejemplificó la campesina Zoraida Archib (ST1) al explicar que "la tierra ya no da como antes, porque ya no se la trabaja cómo antes se hacía, cómo se lo debe hacer". Contó con sentimientos de nostalgia que antes toda la familia trabajaba en conjunto y también había ayuda entre vecinos, había cooperación y solidaridad; se agradecía y veneraba a la tierra, se ahumaba la milpa con copal antes de sembrar, se encendían velas y se la regaba con agua bendita. Después del trabajo se celebraba con atole (bebida mesoamericana a base de maíz) y caldo de gallina.

La manera de "cómo se hacía antes", sinónimo de "cómo se debe hacer", hace referencia a prácticas, valores y conocimientos agri-culturales que cultivan relaciones: con la tierra, la familia, de vecindad, con la comunidad y con el territorio, incluyendo entes espirituales y fuerzas naturales que lo habitan. Encarnación García cuenta cómo antes se cultivaba la tierra en una relación dialógica, mientras hoy la mayoría adoptó el modelo de dominación de la tierra:

[A]ntes, se llegaba a ver la milpa, estaba el copal, se platicaba con Dios y con la milpa. Pero ahora ya no nos acordamos de la bendición del copal, de nada. Somos como son los cambios que hay ahora, pues ahora no platicamos ya con la Santa Tierra, al contrario ... ahora se la contamina, de una vez se mata todo. (AT8)

En las reflexiones sobre la agricultura y los cambios suscitados a lo largo de la vida de las y los campesinos, se destacó el tema generador: "la pérdida de la identidad y del modo de vida campesino", que ellos identifican como causa de la baja fertilidad de la tierra y como afronta principal para una buena vida en el campo, sosteniéndose en una 
agricultura campesina "en armonía con la naturaleza" (SALE, 2019; ASODETTE, 2020). Con base en todo lo señalado, a este quiebre en la agri-cultura campesina se entiende cómo una ruptura ontológica y epistemológica que, sometiéndola en una lógica eficientista, mercantilista $\mathrm{y}$ clientelar, ha llegado a descalificar la identidad campesina, de conjunto con sus correspondientes conocimientos y sus modos de vivir y de trabajar. "El alto rendimiento que les vendieron a los campesinos en esta zona [de distrito de riego] fue lo que llevó al individualismo", analizó la dirigente Concepción Mérida (AT8). La agricultura moderna tiene una lógica muy diferente respecto de la agricultura campesina tradicional, sugiriendo una forma de vida "que no es según el ritmo de la vida" (AV2). La aplicación de insumos químicos ofrece aparentes soluciones inmediatas e implica menos esfuerzo físico, que es la preferencia mayoritaria actual, debido a que "hemos perdido nuestra cultura de trabajo" (ST1). Las y los campesinos destacaron que su identidad comunitaria está siendo desmantelada por una "cultura neoliberal" (DPTA): "Nos dividen y nos cambian, la lógica campesina cambia y pensamos más en el dinero. Pero si no se trabaja en comunidad somos frágiles" (AT4). Muchas problemáticas de las comunidades campesinas analizadas radican en el debilitamiento del principio comunitario, que caracteriza la agricultura campesina. Por ejemplo, en el problema clave de la escasez de agua se resalta la sabiduría de las personas mayores, quienes plantean que "hay que crear comunidad para que se quede el agua" (AT2; AE2).

Las y los campesinos se identifican en relación con la comunidad, con la tierra y con el territorio. Su identidad se expresa en los modos de convivir con la tierra y el saber aprovechar sus frutos (RIP). La temporalidad de la naturaleza en el curso del año tiene un alto significado: "todo tenía su tiempo, un momento indicado" (Roberto Alvarado, AT2). Una serie de celebraciones marcan fechas del año importantes en relación con los ciclos de la naturaleza (por ejemplo, temporadas de lluvias, de vientos, de siembra y de cosecha) y cada celebración o temporada está acompañada de ciertos rituales y comidas típicas (DPTA; RIP). Tradicionalmente, el trabajo en el campo más intensivo, como la siembra y la cosecha, se lleva a cabo por una praxis mancomunada llamada "faina", "cambio de mano" o "mano a mano". De igual importancia que el trabajo lo son el convivio y la celebración comunitaria. "Cuando se cosechaba se hacía una ceremonia con velas y copal, era de unidad 
familiar y también por agradecer a la Santa Tierra por las cosechas" (María del Carmen Mérida, ST2). La agricultura e identidad campesina refleja un ethos de comunalidad (Martínez, 2004) y de relacionalidad, según el cual la Madre Tierra da cuando la comunidad humana también le corresponda con respeto y agradecimiento. La investigación resalta que sin comunidad no hay milpa, no hay agua, no hay territorio - y por lo tanto no puede haber agroecología.

Las y los campesinos entienden la agroecología como manera de "rescatar saberes que nos dijeron que no eran buenos" y de reconstruir "otra forma de vida que promueve la unidad, de relacionarnos con la Madre Tierra, la naturaleza y con nosotros mismos" (AV2). La agricultura campesina agroecológica, según esta concepción holística y relacional, es más que un modo de producción; es un modo de vida, de ver la vida y de estar y ser con la vida, que (re)genera identidad y (sentido de) vida. Es una "constelación de existencia" (Limón, 2010, p. 20 en referencia a Weber, 1922) sostenida por conocimientos históricamente construidos por un grupo cultural en relación con la tierra y el territorio. Estos "conocimientos culturales" (Limón, 2010), que están en una dialéctica con las identidades, cosmovisiones $\mathrm{y}$ modos particulares de existir de un pueblo, describen el tipo de conocimiento encontrado, que aporta a la conceptualización y construcción de una agroecología campesina en un sentido profundo y existencial. Consecuentemente, se propone adoptar esta categoría y adaptarla para el presente análisis como conocimientos agri-culturales. Estos conocimientos se constituyen "en las confluencias de la memoria y la esperanza, como potencia, y cuyo contenido es convocado a redimir el pasado-presente oprimido" (Limón, 2010, p. 28). De ahí se subraya su aporte a la descolonización del saber y ser campesino, tematizada en la sub-sección siguiente.

\section{"Sacar el águila de adentro": la praxis decolonial de una pedagogía agroecológica}

La situación campesina analizada recuerda lo que Freire (1972; 2002) denomina enajenación o invasión cultural. El pedagogo enuncia su carácter deshumanizante, dado que lleva a la "inautenticidad del ser de los invadidos" (Freire, 2002, p. 138) por hacer que responda a los valores, patrones y las finalidades de los invasores $y$, consecuentemente, conduce a la inhibición de su capacidad creadora. La percepción del "despojo invisible" por el dirigente Fernando López (AT1) lo corrobora: 
"Primero nos vacían, diciendo que nuestros costumbres y culturas no sirvan y luego lo llenan con algo diferente. Es despojo invisible y nos convierte en pobres-ricos, pensamos como ricos." En el análisis de esta observación se muestra el mecanismo deshumanizante de interiorizar el opresor (Freire, 2002) y la inferioridad (Fanon, 2009), que conduce a una descampesinización al nivel inmaterial. La reflexión auto-crítica campesina reveló, que la ideología de la modernidad ha inculcado las nociones de desarrollo y de progreso, que han llegado a definir el ser, incluyendo lo que comemos, pensamos, hacemos, creemos, aspiramos, amamos y, finalmente, determina nuestra idea sobre la vida 'deseada' (ASODETTE, 2020).

Comprendiendo que la “'modernización' del proyecto neoliberal hoy implica nuevas formas de ‘colonización'” (Mignolo, 2003, p. 23), se ubica una causa del despojo campesino invisible en un "colonialismo internalizado" (Fanon, 2009, p. 163). Por lo tanto, se resalta la necesidad de basar la educación-investigación agroecológica en una pedagogía decolonial, entendida como "una forma de (des)aprendizaje: desaprender todo impuesto y asumido por la colonización y deshumanización para reaprender a ser hombres y mujeres" (Fanon, 2001, interpretado por Walsh, 2014, p. 34).

En el Proceso se ejerció una pedagogía agroecológica decolonial según la metodología Freireana de (auto-) reflexionar críticamente la propia realidad, el propio ser en relación con ella y el pensamiento sobre ella. A continuación, se ejemplifica este procedimiento metodológico con un análisis colectivo de la situación colonial y su reproducción por “alojar el opresor" (Freire, 2002, p. 113), que es traducido en este ejemplo a "tragarse el águila" (AT4). Esta reflexión colectiva es plasmada en un dibujo (ilustración 2), que resultó de un diagnóstico participativo del territorio en el ejido Verapaz en el municipio Frontera Comalapa (AT4). En un primer momento de su interpretación colectiva, una joven campesina compartió su impresión: 
Ilustración 2 - “La serpiente y el águila”, producto de devolución de un diagnóstico participativo del territorio en el ejido Verapaz por el equipo que abordó el eje de agricultura.

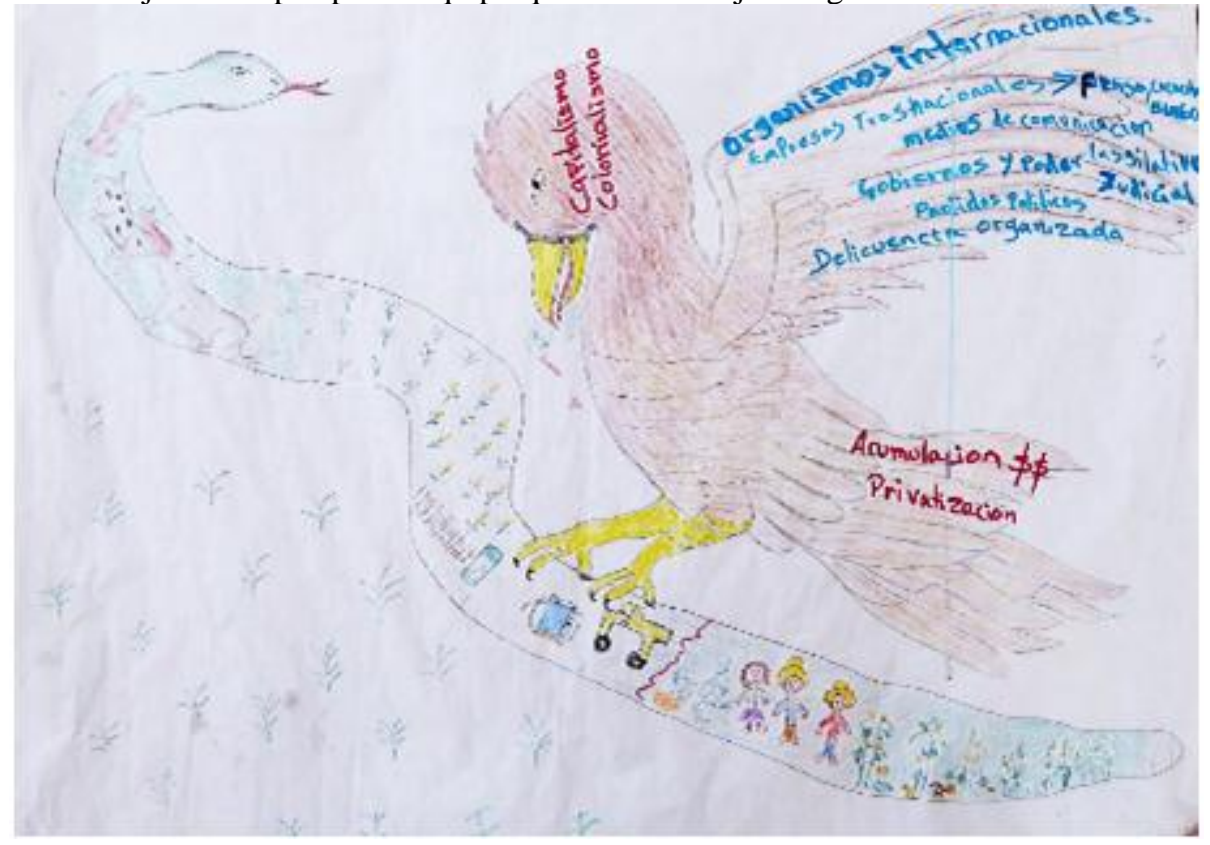

Fuente: Foto tomada por Katrin Aiterwegmair en el cuarto taller de ASODETTE (AT4).

Las alas del águila representan el capitalismo, que nos viene controlando. La serpiente somos el pueblo. Todo lo que contiene el camino de la serpiente es como ... las ideas que han ido viniendo $y$ modificando la forma de pensar, de trabajar y de convivir; también, de alimentarnos. Esto es lo que nos han ido vendiendo y los despojos que tenemos como seres humanos en nuestro medio ambiente. (AT4)

El grupo autor de la obra afirmó esta interpretación y especificó que la intención con la serpiente era "dar a conocer, como una línea de tiempo, el proceso que se ha vivido en Verapaz en el tema de la agricultura". Un integrante del equipo explicó que "en el inicio, en la colita de la serpiente, están las milpas, con unas plantas de frijol, calabaza y cacahuate. Es lo que cultivaban más antiguamente." Otra campesina agregó: "De allí pasó el ciclo, hace treinta, cuarenta años, en la revolución verde, cuando llegó la maquinaria, las bombas, todo eso vino a acabar con nuestro campo, y bueno, se convirtieron en monocultivos"; Un compañero complementa: "Se va utilizando ya químicos, que van dañando ... nuestro suelo, la tierra. Y más adelante, lo que es la actualidad, se dedica más a la ganadería". Se reflexionaron también la relación de poder, que caracteriza el dibujo: El águila es el escudo de la nación y por lo tanto símbolo de poder, mientras la serpiente, representando el pueblo, aparentemente tiene menos poder. No obstante, la serpiente enfrenta al águila, 
observó otro campesino, “está tratando también de defenderse."

Hasta este momento de reflexión se dio una tendencia dualista de distinción del conflicto entre opresor y oprimido. Pero esta imagen simplista fue modificada por una intervención del co-investigador académico José Antonio Meléndez, preguntando "si la serpiente puede tragarse el águila, o sea ¿̇si tenemos dentro de la serpiente una parte del águila?" La respuesta de varios/as participantes fue afirmativa $y$ se esgrimieron algunas reflexiones autocríticas, como la del dirigente Roberto Morales:

Está claro lo que dice Toño, lamentablemente, porque es parte de lo que nos han enseñado a vivir, por el mismo sistema en que vivimos. Es algo que nosotros estamos haciendo el esfuerzo de contrarrestar ... Y este Proceso ... es el mejor camino, porque ... nos han arraigado esa parte y para desarraigar esa parte, pues esto es el camino para conducir a algo diferente, a reconstruir algo que estaba ya tirado al suelo ... Había un dicho que siempre lo usábamos ... en la iglesia: 'somos pobres con pensamiento de ricos', ¿no? O sea, pensamos en lo que es, en lo que tiene un rico, pero no somos pues ... Está como el águila, ¿¿no? ... Nosotros debemos ser, debemos pensar, decidir y hacer que ... en realidad quiénes somos nosotros ... [N]os llevó al final de decir, al final de cuenta yo soy campesino ... qué valor tengo. Creo que eso es el mejor camino, ¿no?, o sea, es la mejor educación. (AT4)
Esta imagen y la conclusión del análisis colectivo de que "hay que sacar el águila de adentro" (AT4), ha alcanzado a constituirse como metáfora para la praxis de descolonización del ser y del saber, usada reiteradamente de los y las campesinos en el Proceso (ver también ilustración 1). La "descolonización de las mentes" marcó los inicios de la OCEZCNPA (SALE, 2019; AT4) influenciados por la impronta de la teología de la liberación; actualmente vuelve a ganar importancia en la coyuntura de una "gubernamentalidad neoliberal” (Gómez et al., 2015) imperante, en la cual "el poder se vuelve opaco instalado en cuerpos particulares" (Castro 2010, citado por Gómez et al., 2015, p. 1743). En el colonialismo internalizado, que está en correlación con la ruptura agri-cultural, se ubica la raíz del reto de emprender procesos autogestivos para fortalecer la agroecología y la soberanía alimentaria. De allí se destaca, que la esencia de una educación e investigación agroecológica es la descolonización de mentes, cuerpos y almas. Una pedagogía campesina decolonial, según nuestra experiencia, puede contrarrestar la negación identitaria y epistémica ejercida por el paradigma de modernidad y re-construir "la habilidad de ser campesinos, de ser dueños del territorio" (Encarnación García, AT10). 
Conocer (desde) las raíces: por una agroecología profunda

Se concluye esta sección de discusión con la conceptualización de resultados epistemológicos revelados y regenerados en el Proceso, que inspiran una concepción y praxis campesina de la agroecología. Retomando la metáfora de la raíz que destaca en las tres ilustraciones usadas como ejemplos del análisis colectivo (en ilustración 2 representada por "la colita de la serpiente"), argumentamos que el conocimiento con potencial transformador está ubicado en las raíces agri-culturales. Se entienden así los conocimientos y "saberes, que se van acumulando en este hecho de ser campesino" y que se mantienen en la memoria biocultural colectiva, como "raíces profundas". A ellas se "tiene que recurrir de manera permanente", porque "quien se desarraiga ... se debilita" (AT2).

Estos saberes, que "condensan una herencia histórico-cultural identitaria" (Barbosa, 2015, p. 45), son ilustrados con otro dibujo (ilustración 3), que resulta de un ejercicio sentí-pensativo de recuperar la memoria biocultural (AT2). Con "el árbol de los ancestros" (ST2), el grupo de trabajo hizo hincapié en que los frutos, que están más cerca a sus abuelos/as, representados con las raíces, son los más grandes. El colectivo autor resumió la reflexión plasmada en su dibujo (ST2):

Ilustración 3 - “El árbol de los ancestros”, producto de un ejercicio de recuperar la memoria biocultural.

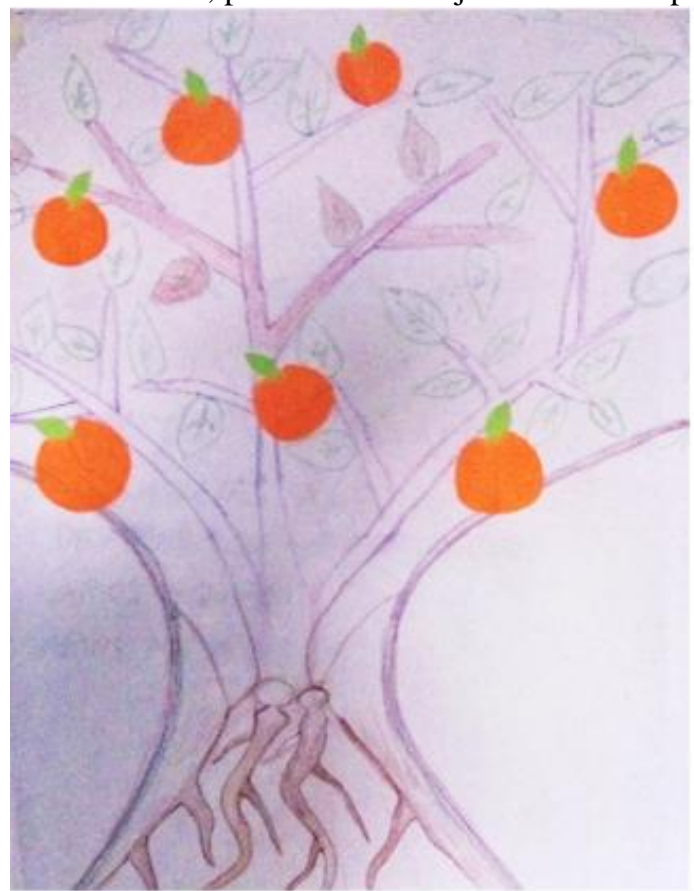

Fuente: Foto tomada por Katrin Aiterwegmair en el segundo taller de SALE (ST2). 
Recordamos que todo lo que aprendimos y sabemos es de nuestros abuelos, quienes son nuestras raíces; de ahí, del tronco para arriba, son nuestros padres; y los gajitos somos nosotros. Donde las hojas están pintadas de rojo, eso representa la OCEZ. El aprendizaje de nuestros abuelos la OCEZ lo ha retomado y por medio de la OCEZ estamos volviendo a recordar y renovar lo de nuestros abuelos. (Dora Isabel López)

Lo que queremos hacer es volver a la cosecha de nuestros abuelos (German Hernández)

Con nuestros abuelos había diversificación de cultivos, la conservación del suelo, no utilizaban agroquímicos, sin saber que es agroecología, y que ahora la organización está tratando de recuperar. Vivían en armonía con la naturaleza, le daban gracias por lo que se estaba produciendo. (Teresa del Carmen Pérez)

De ahí se sostiene que las y los campesinos comprenden la agroecología a partir de los saberes de sus ancestros/as, que "todavía logramos alcanzar" (RIP).

Se destaca que la investigación se ha desarrollado en una "dialéctica de memoria y utopía", misma que sugiere Zemelman (1997) cómo “dimensión de análisis en la construcción de la subjetividad social" (p. 21). A partir de los resultados discutidos se propone este enfoque también para la agroecología, dado que ésta se construye a partir de un sujeto socio-político, cuya propia emancipación fuertemente coincide con la defensa y el desarrollo de las prácticas agroecológicas (Van der Ploeg, 2011). El análisis resalta que la resignificación de la identidad campesina va de acuerdo con la reconstrucción de la agroecología. La memoria biocultural constituye una fuerte raíz identitaria, capaz de resistir a la ideología de modernidad y de nutrir visiones y estrategias de una agricultura agroecológica campesina. De ahí, el hincapié en la praxis de recuperar la memoria histórica, entendida en concordancia con Walsh (2014), como "un espacio ... donde se entreteje en la práctica misma lo pedagógico y lo decolonial" ( $\mathrm{p}$. 9). El proceso de concientización estriba en la reivindicación y la re-significación de una "identidad con fuertes raíces en una cosmovisión milenaria o construidos históricamente", que Barbosa (2015) denomina "ethos identitario" (p. 37). Cabe señalar que la identidad siempre es una construcción social al nivel imaginario, pero justo "las representaciones e imaginarios que poseen las personas" ayudan a "dar sentido y orientar sus prácticas" (Torres, 2000, s.p.).

Efectivamente, al recorrer sus raíces, la OCEZ-CNPA ha encontrado pistas, tanto para re-orientar su praxis sociopolítica y pedagógica como su concepción de la agroecología: "hay que recordar de dónde venimos para saber a dónde vamos" (Concepción Mérida, SALE, 2019). La 
misma dirigente resaltó en una evaluación que "ubicamos dentro de todo el Proceso riquezas, muchos conocimientos, saberes, culturas, que son una gran fortaleza para la organización. De allí podemos detonar, de lo que tenemos, de lo que somos, pues son culturas muy diferentes" (AR1). El Proceso ha servido para resignificar la identidad agri-cultural, como también la identidad sociopolítica campesina al recuperar la experiencia de lucha y los principios fundadores de la organización. Estas raíces, que nacieron en el suelo fértil de la teología de liberación, practicando la educación y culturas populares, organización comunitaria y trabajo de base, se están volviendo a priorizar actualmente. Otro principio ideológico, la lucha de Zapata por la tierra, también se ha resignificado en el Proceso:

Cuando hablamos de tierra $\mathrm{y}$ territorio, estamos refiriendo a cómo defender la tierra como decía Zapata: la tierra es de quien la trabaja; pero también cómo la trabajamos y cómo no vamos a permitir que otros, porque tienen el poder, porque tienen el dinero, nos van a sacar de la tierra, ... de lo que nuestros antepasados nos dejaron por herencia. (Encarnación García, AT10)

La OCEZ-CNPA (2019) manifiesta que "la agroecología ... responde a una estrategia política y surge de la cosmovisión y práctica campesina e indígena que refleja un modo de relacionarnos con la madre naturaleza". A partir de esta noción, ilustrada con varios ejemplos en el presente trabajo, se propone la concepción de una "agroecología profunda", de acuerdo con Botelho et al. (2016), García et al. (2019, pp. 1-2) y McFadden (2019). La investigación sugiere la profundización de la agroecología como tercera dimensión de la territorialización de la agroecología, añadiéndola a las dimensiones vertical (scaling-up), $\mathrm{y}$ horizontal (scaling-out; IIRR, 2000, citado por Mier y Terán et al., 2018). Si se compara la territorialización de la agroecología con el crecimiento de un árbol, y el deseo es que crezca ancho y alto, hay que abonar sus raíces, que se ubican en el suelo fértil de una agri-cultura campesina histórica. Una agroecología profunda busca re-conocer estas raíces e investigar sus características y abonos.

Se sostiene con la investigación que las raíces profundas del conocimiento y de la conciencia, que animan la praxis agroecológica, se ubican en la identidad y el modo de vida campesino. En este nivel ontológico se construye un sentido de vida desde los sentires y los valores agriculturales, que se encuentra en concordancia con la agroecología y la extiende por una dimensión más profunda. Lo profundo remite a la dimensión espiritual y afectiva, que caracteriza la 
agri-cultura campesina y se manifiesta en una disposición de relación dialógica entre sociedad y naturaleza. La motivación más profunda de las y los campesinos para la agroecología surge de su amor por la tierra y por la familia (incluyendo las generaciones pasadas y futuras), cuya salud consideran en interrelación (SALE, 2019). En la cosmovisión campesina e indígena, la tierra no es concebida "como un instrumento, no como objeto, sino como un ser vivo" (Concepción Mérida, AT10). El valor intrínseco y sacro y el carácter holístico y relacional de la "Santa Madre Tierra" (ASODETTE, 2020), que destacan las y los campesinos, también es enfatizado en el concepto de ecología profunda (Naess, 1987), inspirando una agroecología profunda.

Se observó en el Proceso que, al reivindicar su identidad, definida por "nuestro vínculo directo con la tierra" (RIP), las y los campesinos han fortalecido su identificación como "aliados de la tierra" (Encarnación García, AT10). Esta búsqueda de la "vocación ontológica" (Freire, 1972, p. 20) remite al principio de “auto-realización” que Naess (1987, p. 35) destaca en su concepción de la ecología profunda: "al defender la tierra, defendemos a nosotros mismos" (Naess, interpretado por McFadden 2019, p. 98). La profundización de la agroecología sucede, según García et al. (2019), cuando campesinos/as (re)afirman su identidad de manera continua al defender su modo de vida. En este nivel profundo de la agroecología, al que llevó la investigación campesina y transdisciplinaria, convergen la re-significación de la propia identidad con la re-construcción de la vida (buena) en el campo. Al encontrarse en el camino de la agroecología, entran en una simbiosis entre almas y territorios, que inspira otras formas de pensar, sentir y habitar a la tierra.

\section{Conclusión}

La experiencia investigativa resalta que la agroecología se construye a través de un diálogo transdisciplinario y situado, que parte de la identidad, la historia y el territorio particular de las y los campesinos. El conocimiento campesino con potencia transformadora en relación a la agroecología es su conocimiento agricultural, que se nutre de la memoria biocultural, de la experiencia y el modo de vida campesino, y su reflexión (auto)crítica y colectiva.

El tema generador sobre la "pérdida de la identidad y del modo de vida campesino", que resaltaron las y los campesinos contactando con un dolor profundo, remite a las maneras agriculturales de ser y de saber relacionarse 
con la vida en el territorio. La identidad campesina se define por la interrelación con el territorio, la comunidad y la tierra, entretejidos por el hilo de lo sagrado. Por lo tanto, en la reivindicación de la identidad y de la memoria biocultural, en que se funda la agricultura campesina, se ubica una estrategia de resistencia al paradigma de la modernidad y una potencia epistémica, ontológica y sociopolítica clave para la transición agroecológica.

Cabe destacar que la agroecología no se limita a reivindicar el pasado, por lo tanto, el conocimiento agri-cultural se favorece al ser renovado a través de la experimentación y un diálogo de saberes entre campesinos/as y con otras formas de conocimiento. No obstante, la condición para un diálogo transdisciplinario horizontal es el reconocimiento y la revaloración de las identidades, historias y cosmovisiones, en las cuales se fundan los conocimientos campesinos sobre la agroecología.

Evaluando los resultados del Proceso, se sostiene que el mismo ha informado el quehacer político-pedagógico y a la vez ha inspirado la construcción de teoría a partir de la praxis. La recuperación y re-construcción de las raíces agriculturales campesinas dieron luz tanto para la re-significación de la subjetividad campesina y la re-orientación de su praxis socio-política, además de la concepción teórica, metodológica, política y práctica de una agroecología campesina situada. Cabe destacar la necesidad de situar la investigación en el lugar epistémico campesino para prevenir que la agroecología sea cooptada por el agronegocio (Giraldo \& Rosset, 2018) para terminar como mera tecnología, amputada de sus orígenes campesinos y principios políticos de transformación. Contrarrestando esta amenaza, se plantea la apuesta por una agroecología profunda, que reconoce y rescata las raíces agriculturales de las y los campesinos.

La concepción de una agroecología profunda, según la cual no solamente se cultiva la tierra, sino también la relación con ella, plasma el sentido de las agriculturas campesinas e indígenas en Mesoamérica y en muchas otras partes del mundo. Esta ontología campesina fundamenta una epistemología que difiere del paradigma hegemónico. Se resalta desde la experiencia investigativa que dicha epistemología se revela al unir el pensamiento, los afectos, la creatividad, la espiritualidad y la estética, y al darle una dimensión comunitaria. Esta unidad de conocimiento caracteriza las epistemologías de muchos pueblos y se ofrece como un paradigma alternativo al 
Aiterwegmair, K., Mier y Terán, G. C. M., Limón, A. F., Vilsmaier, U., Merçon, J., López, H. J. F., \& Martínez, V. R. (2021). Recreando agri-cultura: Conocimientos agroecológicos e identidades campesinas en un proceso de educación-investigación-acción en Chiapas, México...

moderno que ha generado la crisis civilizatoria actual.

\section{Agradecimientos}

Expresamos nuestro profundo reconocimiento y agradecimiento al aporte de cada una y uno que nutrió este proceso colectivo de construcción de conocimiento y praxis, destacándose las y los investigadores, coordinadores $\quad \mathrm{y}$ facilitadores de la OCEZ-CNPA, del IMDEC y del Instituto Paulo Freire Austria.

\section{Referencias}

Altieri, M., \& Toledo, V. M. (2010). La revolución agroecológica de América Latina. Rescatar la naturaleza, asegurar la soberanía alimentaria y empoderar al campesino. El Otro Derecho, 42, 163-202.

Barbosa, L. (2015). Educación, resistencia y movimientos sociales: la praxis educativo-política de los Sin Tierra y de los Zapatistas. México: UNAM.

Botelho, M. I., Cardoso, I. M., \& Otsuki, K. (2016). "I made a pact with God, with nature, and with myself": exploring deep agroecology. Agroecology and Sustainable Food Systems, 40(2), 116-131. https://doi.org/10.1080/21683565.2015.11 15798

Fals Borda, O. (1979). El problema de cómo investigar la realidad para transformarla. Bogotá: Federación para el Análisis de la Realidad Colombiana.

Fanon, F. (2001 [1963]). Los condenados de la tierra. México: Fondo de Cultura Económica.
Fanon, F. (2009 [1952]). Piel negra, máscaras blancas. Madrid: Akal. https://doi.org/10.7476/9788523212148

Freire, P. (1972). Sobre la acción cultural. Santiago de Chile: ICARA.

Freire, P. (2002 [1970]). Pedagogía del oprimido. Madrid: Siglo XXI.

García, V., Giraldo, O., Morales, H., \& Rosset, P. (2019). Seed sovereignty and agroecological scaling: two cases of seed recovery, conservation, and defense in Colombia. Agroecology and Sustainable Food Systems, 43(7-8), 827-847. https://doi.org/10.1080/21683565.2019.15 $\underline{78720}$

Giraldo, O. (2018). La ecología política de la agricultura. Agroecología y posdesarrollo. San Cristóbal de Las Casas: El Colegio de la Frontera Sur.

Giraldo, O., \& Rosset, P. (2018). Agroecology as a territory in dispute: between institutionality and social movements. The Journal of Peasant Studies, 45(3), 545-564. https://doi.org/10.1080/03066150.2017.13 $\underline{53496}$

Glaser, B. G., \& Strauss, A. L. (1967). The Discovery of Grounded Theory. Strategies for Qualitative Research. Chicago: Aldine. https://doi.org/10.1097/00006199196807000-00014

Gliessman, S. R. (1981). Aspectos ecológicos de las prácticas agrícolas tradicionales en Tabasco México: aplicaciones para la producción. Biótica, 5(3), 93-101.

Gómez, F., Ríos Osorio, L., \& Eschenhagen, M. L. (2015). Las bases epistemológicas de la agroecología. Agrociencia, 49(6), 679-688. 
Gómez, L., Jódar, A., \& Bravo, M. J. (2015). Gubernamentalidad neoliberal y producción de conocimiento en la universidad: genealogía de una configuración subjetiva. Universitas Psychologica, 14(5), 1735-1750. https://doi.org/10.11144/Javeriana.upsy145.gnpC

Guattari, Felix (2015 [1992]): Transdisciplinarity must become transversality. Theory, Culture, Society, 32(5-6), 131-137. https://doi.org/10.1177/026327641559224 $\underline{5}$

Guevara, E. (2003 [1965]). Der Sozialismus und der Mensch in Kuba. Brief an Carlos Quijana. En Gross, HorstEckart (Ed.). Ernesto Che Guevara: Der neue Mensch (pp. 14-36). Bonn: PahlRugenstein.

Harvey, D. (2007). Breve historia del neoliberalismo. Madrid: Akal.

IAASTD. (2009). Agriculture at a Crossroads. Global Report. Washington D.C.: Island Press.

IPES-Food. (2016). From uniformity to diversity: a paradigm shift from industrial agriculture to diversified agroecological systems. En International Panel of Experts on Sustainable Food systems. Recuperado de: http://www.ipesfood.org/_img/upload/files/UniformityToD iversity_FULL.pdf

Jara, O. (2012). Sistematización de Experiencias, Investigación, Evaluación: Aproximaciones desde tres ángulos. The International Journal for Global and Development Education Research, 1(2), 56-70.

Leff, E. (2006). Aventuras de la epistemología ambiental. México: Siglo XXI.
Limón, F. (2010). Conocimiento cultural y existencia entre los chuj. México: CDI.

Limón, F. (2019, 14 de mayo). La sacralidad como principio agroecológico básico en el pueblo maya-chuj. Ponencia en el Primer Congreso Mexicano de Agroecología, San Cristóbal de las Casas, Chiapas.

Martínez, J. (2004). Comunalidad y desarrollo. México: CONACULTA.

McFadden, S. (2019). Deep agroecology: Farms, food, and our future. Nebraska: Light and Sound Press.

Méndez, V. E., Bacon, C. M., \& Cohen, R. (2013). Agroecology as a Transdisciplinary, Participatory, and Action-Oriented Approach. Agroecology and Sustainable Food Systems 37(1). https://doi.org/10.1201/b19500-2

Merçon, J., Ayala-Orozco, B., \& Rosell, J. (2018). Experiencias de colaboración transdisciplinaria para la sustentabilidad. Serie Construyendo lo Común. Buenos Aires: Comunidad Editora Latinoamericana.

Mignolo, W. D. (2003). Historias locales/diseños globales. Colonialidad, conocimientos subalternos y pensamiento fronterizo. Madrid: Akal.

Mier y Terán, M., Giraldo, O., Aldasoro, M., Morales, H., Ferguson...Campos, C. (2018). Bringing agroecology to scale: key drivers and emblematic cases. Agroecology and Sustainable Food Systems, 42(6), 637665.

https://doi.org/10.1080/21683565.2018.14 $\underline{43313}$

Nájera, E. (2018). Acción colectiva y movimiento social: transiciones en la lucha campesina de la OCEZ-CNPA, Chiapas (Tesis de Maestría). El Colegio de 
la Frontera Sur, San Cristóbal de las Casas, México.

Naess, A. (1987). Self-realization: An Ecological Approach to Being in the World. The Trumpeter, 4(3), 35-41.

Nicolescu, B. (2008). In vitro and in vivo knowledge. En Nicolescu, B. (Ed.). Transdisciplinarity. Theory and Practice (pp. 1-22). Cresskill: Hampton Press.

OCEZ-CNPA. (2015). 1980-2015. 35 años de lucha. Comunicado interno.

OCEZ-CNPA. (2019). Aportes para la reflexión desde la Organización Campesina Emiliano Zapata. Folleto de difusión para el II. Campamento Nacional de Agroecología.

Pimbert, M. (2006). Transforming knowledge and ways of knowing for food sovereignty. London: International Institute for Environment and Development.

Reichertz, J. (2007). Abduction: The Logic of Discovery of Grounded Theory. En Bryant, A., \& Charmaz, K. (Eds.). The Sage Handbook of Grounded Theory (pp. 214-229). London: Sage. https://doi.org/10.4135/9781848607941.n1 $\underline{0}$

Rosset, P. M., \& Martínez, M. E. (2014). Diálogo de saberes in La Vía Campesina: food sovereignty and agroecology. Journal of Peasant Studies, (41)6, 979-997, https://doi.org/10.1080/03066150.2013.87 $\underline{2632}$

Rosset, P. M., \& Martínez, M. E. (2016). Agroecología, territorio, recampesinización y movimientos sociales. Estudios Sociales, 25(47), 275-299.

Ruiz, O. (2006). Agroecología: una disciplina que tiende a la transdisciplina. Interciencia, 31, 140-145.
Santos, B. (2010). Descolonizar el Saber. Reinventar el Poder. Montevideo: Trilce.

Sevilla, E. (2006). De la Sociología Rural a la Agroecología. Barcelona: Icaria.

Toledo, V. M., \& Barrera-Bassols, N. (2008). La memoria biocultural. La importancia ecológica de las sabidurías tradicionales. Barcelona: Icaria.

Torres, A. (2000). Educación Popular, subjetividad y sujetos sociales. Pedagogía y Saberes, 15. s.p.

UNCTAD. (2013). Wake up before it is too late: Make agriculture truly sustainable now for food security in a changing climate. Trade and Environment Review $2013 . \quad$ Recuperado de: http://unctad.org/en/PublicationsLibrary/dit cted2012d3_en.pdf

Van Der Ploeg, J. D. (2010). Nuevos campesinos. Campesinos e imperios alimentarios. Barcelona: Icaria.

Van der Ploeg, J. D. (2011). The drivers of change: the role of peasants in the creation of an agro-ecological agriculture. Agroecología, 6, 47-54.

Vilsmaier, U., Engbers, M., Luthardt, P., Maas-Deipenbrock, R. M., Wunderlich, S., \& Scholz (2015). Case-based Mutual Learning Sessions: knowledge integration and transfer in transdisciplinary processes. Sustainable Science, 10, 563-580. https://doi.org/10.1007/s11625-015-0335-3

Vilsmaier, U., Brandner, V., \& Engbers, M. (2017). Research in-between: The constitutive role of cultural differences in Transdisciplinarity. Transdiciplinary Journal for Engineering \& Science, 8, 169179. https://doi.org/10.22545/2017/00093

Walsh, C. (2014). Lo pedagógico y lo decolonial: Entretejiendo caminos. Querétaro: Encortito que's pa' largo. 
Wezel, A., Bellon, S., Doré, T., Francis, C., Vallod, D., \& David (2009). Agroecology as a science, a movement and a practice: a review. Agronomy for Sustainable Development 29, 503-515. https://doi.org/10.1051/agro/2009004

Xolocotzi, E., \& Zárate, M. A. (1991). Agricultura tradicional y conservación de recursos genéticos in situ. En Ortega, R., Palomino, G., Castillo, F., \& Livera (Eds.). Avances en el estudio de los recursos fitogenéticos de México (pp. 9-11). México: Universidad de Chapingo.

Zemelman, H. (1997). Sujetos y subjetividad en la construcción metodológica. En Zemelman, H., \& León, E. (Eds.). Subjetividad: umbrales del pensamiento social (pp. 21-35). México: Anthropos.

\section{Fuentes primarias}

AE2: $2^{\circ}$ Encuentro Transfronterizo de ASODETTE (con aliados/as de la Coalición Indígena de Migrantes de Chiapas de Los Altos de Chiapas y del Gobierno Ancestral Plurinacional de Guatemala), Ejido Rubén Jaramillo, La Trinitaria, 25 a 27 de abril de 2019

AR1: $1^{\circ}$ reunión de evaluación anual de ASODETTE, 6 de febrero 2019

AT1: $1^{\circ}$ taller de ASODETTE, Ejido 24 de Febrero, Frontera Comalapa, 16 a 17 de febrero de 2018

AT2: $2^{\circ}$ taller de ASODETTE, Ejido Rubén Jaramillo, La Trinitaria, 4 a 7 de abril de 2018

AT4: $4^{\circ}$ taller de ASODETTE, Ejido Verapaz, Frontera Comalapa, 17 a 19 de agosto de 2018
AT8: $8^{\circ}$ taller ASODETTE, Santa Martha, La Trinitaria, 10 a 11 de octubre de 2020

AT9: $9^{\circ}$ taller ASODETTE, Santa Martha, La Trinitaria, 23 a 24 de octubre de 2020

AT10: $10^{\circ}$ taller ASODETTE, Santa Martha, La Trinitaria, 18 a 19 de diciembre de 2020

AV2: $2^{\circ}$ visita de seguimiento, Ejido Guadalupe Grijalva, Frontera Comalapa, 13 a 15 de diciembre de 2019

ASODETTE (2020): protocolo del proceso ASODETTE (2018-2020)

DPTA: Sistematización del Diagnóstico Participativo del Territorio en el proceso ASODETTE (2018-2019)

RIP: Reunión de investigación de praxis, Santa Martha, La Trinitaria, 7 de marzo de 2021

SALE (2019): protocolo del proceso SALE (2016-2018)

ST1: $1^{\circ}$ taller de SALE, Santa Martha, La Trinitaria, 26 de julio de 2016

ST2: $2^{\circ}$ taller de SALE, Santa Martha, La Trinitaria, 7 de febrero de 2017

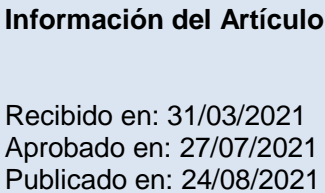

Contribuciones en el artículo: Los autores fueron responsables de todas las etapas y resultados de la investigación, a saber: preparación, análisis e interpretación de los datos; redacción y revisión del contenido del manuscrito y; aprobación de la versión final publicada.

Conflictos de Intereses: Los autores han declarado que no existe conflicto de intereses con respecto a este artículo. 


\section{Evaluación del artículo}

Revisión por pares

\section{Agencia de Desarrollo}

Consejo Nacional de Ciencia y Tecnología del Gobierno Mexicano.

\section{Cómo citar este artículo}

APA

Aiterwegmair, K., Mier y Terán, G. C. M., Limón, A. F., Vilsmaier, U., Merçon, J., López, H. J. F., \& Martínez, V., R. (2021). Recreando agri-cultura: Conocimientos agroecológicos e identidades campesinas en un proceso de educación-investigación-acción en Chiapas, México. Rev. Bras. Educ. Camp., 6, e11925. http://dx.doi.org/10.20873/uft.rbec.e11925

\section{ABNT}

AITERWEGMAIR, K.; MIER Y TERÁN, G. C. M.; LIMÓN, A., F.; VILSMAIER, U.; MERÇON, J.; LÓPEZ, H. J. F.; MARTíNEZ, V. R. Recreando agri-cultura: Conocimientos agroecológicos e identidades campesinas en un proceso de educación-investigación-acción en Chiapas, México. Rev. Bras. Educ. Camp., Tocantinópolis, v. 6, e11925, 2021. http://dx.doi.org/10.20873/uft.rbec.e11925 